\title{
Nuevos soportes, nuevos modos de leer. La narrativa en la Literatura infantil y juvenil digital
}

\section{Franco, María del Carmen Rosas}

Resumen:

En la literatura infantil y juvenil digital, las tecnologías se utilizan no sólo para la creación de la narrativa sino también para su transmisión y recepción, a través de las pantallas como interfaz privilegiada. En ellas se incluyen elementos multimodales; es decir, a texto e imágenes se unen sonidos, animación, interactividad y componentes hipertextuales que apelan al lector activo, convirtiéndolo en un hiperlector. De esta manera la narrativa, como género, expande sus posibilidades. El presente artículo se adentra de manera crítica en el panorama de las manifestaciones literarias virtuales, en específico, las de la literatura infantil y juvenil, desde

Cuadernos del Centro de Estudios de Diseño y Comunicación Nº72

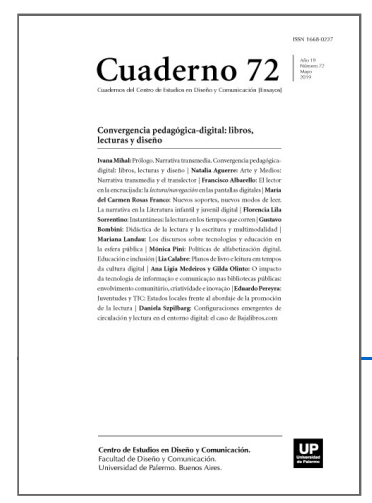

ISSN: 1668-0227

Convergencia

pedagógica-digital:

libros, lecturas y

diseño

Año XIX, Mayo 2019, Buenos Aires,

descargar PDF

ver índice de la publicación

Ver todos los libros de la publicación

compartir en Facebook

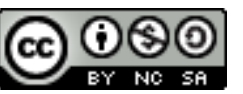

Esta obra está bajo una Licencia Creative Commons Atribución-NoComercialCompartirlgual 4.0 Internacional

el análisis interdisciplinar.

Palabras clave: Narrativa digital - Literatura infantil y juvenil - hipertexto - hiperlector.

$\left({ }^{*}\right)$ Máster en Estudios de Arte y doctoranda en Letras Modernas por la Universidad Iberoamericana, México. Con estudios de licenciatura en Diseño Gráfico, especialidad en editorial. Sus áreas de investigación son en narrativas digitales, literatura infantil y juvenil, arte-tecnología y narrativa gráfica. Docente de diferentes universidades en México. Ha colaborado con editoriales mexicanas como diseñador-editor gráfico; en revistas, blogs como escritora de artículos relacionados con LIJ en especial narrativa gráfica y digital.

Introducción

Hace décadas que el internet y las tecnologías de la comunicación nos alcanzaron, el acceso a la información en la actualidad es por medio de las plataformas digitales que se encuentran bajo un mismo techo, la pantalla. A través de la pantalla del celular, de la computadora, la tableta, la televisión de plasma, el reloj digital y otros dispositivos electrónicos, nos inmiscuimos en un mundo que no parece otro sino el que habitamos. 
Lo que nos dejó la era industrial fue la producción en masas en un tiempo y espacio determinados; a lo que sucedió la era de la información que mostró la misma economía a gran escala, pero con menor énfasis en el tiempo y el espacio. Nuestra era, la de la postinformación, no tiene límites espaciales ni temporales incluso, no tiene límites geográficos (Negroponte, 1995, p. 13-18).

Todo lo que circula en la vida "real" se encuentra en el vasto universo de lo digital al mismo nivel de lo "irreal", de lo fantástico; ese mundo digital está plagado de narrativas que nos atrapan y con las que interactuamos constantemente.

Quienes han encontrado mayor afinidad en ese espacio son los niños y jóvenes que nacieron a la par de la tecnología digital. Herederos de la cultura pop, las series de televisión, los dibujos animados y un sin fin de objetos culturales producto de la globalización y el mercado de masas; los millenials interactúan de forma natural con estas narrativas; al tiempo que acceden a ellas las intervienen, las copian en sus muros, las editan, les toman foto, las aprueban o desaprueban, las recomiendan a sus amigos. Los soportes digitales que son parte de su cotidianeidad han transformado los modos de leer y están transformando las formas de creación literaria y artística.

La "Primera Encuesta Nacional sobre Consumo de Medios Digitales y Lectura" realizada en México en 2015 señala que, la mayor parte del consumo de productos digitales lo realizan niños y jóvenes de estrato social medio-alto en zonas donde hay acceso a servicios de internet y telefonía. De los jóvenes encuestados, el 93\% cuenta con un smartphone o algún otro dispositivo electrónico: consolas de videojuegos, reproductores de video y música, tabletas. Independientemente de la edad, el acceso a internet satisface una necesidad funcional y emocional entre los jóvenes de 12 a 19 años, prácticamente todas sus actividades giran en torno a esta herramienta.

Si bien los medios digitales son usados en mayor medida para la comunicación interpersonal, cerca de la mitad de la población infantil y juvenil hace uso de estos para informarse y leer de modos diferentes a los tradicionales. La lectura que hacen no sólo se limita a los textos, también es una lectura de imágenes y contenidos audiovisuales, lo que refiere a prácticas letradas contemporáneas.

Entre los hábitos más marcados de lectura por iniciativa propia de niños y jóvenes se observa una preferencia por leer noticias, artículos, blogs, tips, reseñas o tutoriales, contenidos de formato corto que se leen en gran volumen a través de las pantallas.

Debido a los cambios surgidos con las tecnologías de la comunicación y de cómo se han modificado las formas de consumo de textos escritos y visuales, la Literatura infantil y juvenil (LIJ) digital se ha convertido en un fenómeno que escapa de las disciplinas convencionales, su definición, análisis y posible clasificación son complejos; por este motivo es necesario acercarnos a ella de manera crítica, tratando de comprender sus características y posibilidades, definiéndola como una neovanguardia literaria que está replanteando los conceptos de literatura, lectura y lectores.

La LIJ antes de la era digital 
La LIJ tiene ya de por sí una larga tradición de ruptura y subversión, está siempre en constante cambio. El siglo XVII se considera su periodo de reconocimiento, sin embargo, es en la época posmoderna donde toma protagonismo gracias al desarrollo de un mercado editorial específico y las demandas del público infantil y juvenil.

La era posmoderna donde emerge la LIJ como fenómeno cultural y social está marcada por la incredulidad a los metarrelatos que surgieron en la crisis postindustrial, es una mezcla entre ruptura y continuidad. El mismo prefijo pos alude a un estadio entre dependencia e independencia de aquello que temporalmente lo antecede y que también hace posible su existencia (Guerrero, 2016, p. 107-109).

Las formas literarias a finales del siglo XIX usaron distintos lenguajes como la imagen, los elementos gráficos y el diseño, y tienen su legitimación en la posmodernidad del siglo XXI. Así lo comprueba el desarrollo del cómic, la novela gráfica y el libro álbum:

Como fenómeno de masas ligado a la industria cultural, el cómic nace en Estados Unidos a finales del siglo XIX, incluido en periódicos y revistas, y más tarde en álbumes. Constituido por la secuencia progresiva de imágenes y elementos de escritura fonética encerrados en los globos y en los comentarios. El cómic tiene, en virtud de una original presentación del código icónico y verbal, el carácter de lenguaje dotado de autonomía expresiva y comunicacional, con una gramática y sintaxis propias. En el cómic por antonomasia, palabra e imagen se encuentran en relación de reciprocidad y armónica integración, aunque la segunda predomina sobre el texto escrito. (Nobile, 1992, p. 97)

Las vanguardias literarias del siglo XX hicieron lo suyo en la explosión de las narrativas gráficas, iniciando una época de ruptura con la tradición. Con ellas surge una estética que privilegia la imagen sobre el texto; a veces la imagen está al servicio del texto, otras veces se integran y complementan e incluso, en ocasiones, la palabra tiende a desaparecer y recae en la imagen la función narrativa.

En las obras literarias de la vanguardia los elementos plásticos y los literarios se articulan creativamente con un sentido artístico, facilitando y estimulando la lectura, contribuyendo así al acercamiento al texto. Su surgimiento puso de manifiesto que los límites entre los géneros y las prácticas artísticas son flexibles, que el encuentro entre la imagen y la palabra puede ser creativo y estimulante para el receptor, incluso, necesario para la construcción de la obra (Rey, 2000, p. 320).

La LIJ llegó a su máxima expresión con sus narrativas gráficas y formatos permisibles en la última mitad del siglo XX, la creación artística enfocada a producir narraciones para niños y jóvenes se renueva una vez más para dar paso a narrativas que, valiéndose de las tecnologías actuales cuestionan los modos de crear historias.

Llega el momento de que la narrativa se libere de la forma física del papel, que expanda sus posibilidades por encima de lo tangible para poner sus cimientos en un nuevo espacio, la pantalla. Las narrativas digitales del siglo XXI son mezcla de la ruptura y continuidad que caracterizan a la posmodernidad, son una nueva forma de literatura.

Nobile hablaba ya en 1992 de un vasto repertorio de narrativas diferentes a los libros tradicionales de LIJ y defendía sus características como un lenguaje posible: 
Cualquiera que sea la valoración psicopedagógica, estética, ética y social que se pueda hacer de estos nuevos lenguajes visuales (que en ocasiones han sido despreciados por los defensores de la lengua escrita, por ser ésta, según ellos una forma más elevada del discurso), es innegable su creciente uso y función narrativa. La imagen fija (ilustraciones, cómics, carteles publicitarios) y en movimiento (cine, televisión, video, multimedia, videojuegos) es hoy la protagonista de nuestro universo de comunicación, bien usada, ya sea subordinada al texto o de manera independiente, en estrecha relación de interpretación narrativa con él. Hoy día se debe reconocer al código icónico el carácter de un lenguaje autónomo, capaz de servir de vehículo, tal vez hasta de forma más eficaz que la palabra escrita, a contenidos y mensaje. Incluso se dice que la imagen, como la lengua verbal, el sonido musical, el gesto, pertenece al universo del lenguaje como posibilidad de simbolización, expresión, comunicación.

Es así que se debe dar el crédito al signo gráfico-visual, la capacidad de reflejar todas las experiencias y elementos de naturaleza perceptiva, táctil, cinestésicas que en otras formas de comunicación estarían destinadas a perder gran parte de su identidad. Se debe pensar en una interacción entre palabra escrita e imagen, en el reconocimiento de la relación de complementariedad existente entre libro y medios de comunicación. (Nobile, 1992, p. 86-87)

En las narrativas digitales de LIJ finalmente se conjugan en uno solo todos los lenguajes usados con anterioridad, algunos relegados por considerarse parte de una cultura del entretenimiento: el texto y la palabra escrita; la imagen fija y en movimiento; el lenguaje sonoro y el verbal, todos se incluyen de manera armónica.

También el avance en la tecnología, el desarrollo de software y la programación por computadora son clave para que la narrativa sea creada y procesada desde un dispositivo electrónico para acceder a ella de manera digital, la narrativa ya no depende de un sólo formato.

Las empresas que producen tecnología (Macintosh, Google, Microsoft) se sumaron al desarrollo y creación de la narrativa digital, en primer lugar con la venta y distribución en el mercado de dispositivos para la lectura de textos, imágenes y sonidos: en segundo lugar han hecho un llamado a artistas, creativos, informáticos, diseñadores de videojuegos y aplicaciones, a crear y difundir sus historias a través de diversos canales (YouTube, Instagram, Facebook, Vimeo, Tumblr), abriendo la comunicación entre estos y los usuarios, tratando así de satisfacer necesidades de consumo.

En la búsqueda de esta interacción se inventan narrativas que tienen como base la comunicación en redes sociales, a través de dispositivos touch que permiten cambiar las historias desde la misma pantalla, ya sea insertando contenidos, descargando aplicaciones, haciendo uso de buscadores gps e infinidad de herramientas que se agregan para convertir a los lectores en coautores.

Al mismo tiempo, se mezclan disciplinas diferentes que intervienen para crear historias plasmadas en la pantalla: la literatura, las artes visuales, la animación, lo que deviene en una característica transmediática, un conglomerado de prácticas culturales y artísticas.

Lo transmedia es un proceso en el que los elementos integrales de una obra de ficción se esparcen sistemáticamente por varios canales de distribución con el propósito de crear una experiencia de entretenimiento 
unificada y coordinada. Lo ideal es que cada medio proporcione su propia contribución original al desarrollo de la historia. (Jenkins, 2011, párr. 4, s/n)

No se trata sólo de trasladar un libro impreso a un formato digital, su creación implica la construcción de una gran historia por medio de pequeñas historias, que, a través de diferentes medios -incluso los del libro- van sumando significados a la trama original.

El juego para celulares Pokémon Go es ejemplo claro de esta característica transmediática presente en las narrativas digitales de LIJ. El relato inicial comenzó con un videojuego llamado Pocket Monsters Aka and Midori (1996) creado en Japón para la consola portátil Game Boy de Nintendo, que cambió su nombre a Pokémon para la versión de los Estados Unidos. Gracias al éxito obtenido con el videojuego, posteriormente se crearon una serie y una película de dibujos animados (1997) que forman parte de un anime metaserial basado en la historia inicial.

En 1999, salen al mercado las cartas coleccionables, que son un juego de mesa donde los participantes desempeñan el papel de los personajes, pasando así de la pantalla a la realidad. Sin dejar la línea de las tres narrativas anteriores: el videojuego, la serie de televisión y las cartas, se agregó una cuarta historia; la del manga.

Para 2016, se crea la versión del juego en realidad aumentada que basa su sistema en la geolocalización por medio de celulares inteligentes: Pokémon Go es una revolución que supera todos los juegos para celular existentes hasta el momento. Mediante la descarga gratuita de la app -disponible para plataformas iOS y Android-, el jugador debe buscar y capturar pokémones escondidos en casi cualquier parte del mundo en el que nos encontramos; la realidad y la fantasía se unen haciendo que el usuario interactúe de manera física con los personajes de Pokémon.

Pokémon Go continúa con la historia inicial, la del videojuego, y ha sumado las otras historias: las de la serie de televisión, la película, las cartas, el manga, para crear una macrohistoria. La línea narrativa de Pokémon ha sido aceptada por usuarios de más de 20 países alrededor del mundo, obteniendo un éxito rotundo, lo que deja implicaciones económicas importantes para Google y Pokémon Company International, las empresas que lo lanzaron al mercado. El alcance de las narrativas digitales de LIJ que rebasan el mundo virtual para insertarse en la realidad demuestra que, el lector ha dejado de ser pasivo para convertirse en un lector que interactúa con la obra y el autor, evidenciando además que el envase no debe encerrar jamás a la obra. Decía Barthes que el autor ha muerto y en su lugar ha dado paso al lector:

[...] de esta manera se desvela el sentido total de la escritura: un texto está formado por escrituras múltiples, procedentes de varias culturas y que, unas con otras, establecen un diálogo, una parodia, un cuestionamiento; pero existe un lugar en el que se recoge toda esa multiplicidad, y ese lugar no es el autor, como hasta hoy se ha dicho, sino el lector: el lector es el espacio mismo en que se inscriben, sin que se pierda ni una, todas las citas que constituyen una escritura; la unidad del texto no está en su origen, sino en su destino, pero este destino ya no puede seguir siendo personal: el lector es un hombre sin historia, sin biografía, sin psicología; él es tan solo ese alguien que mantiene reunidas en un mismo campo todas las huellas que constituyen el escrito [...]. (Barthes, 1968) 
El autor y la obra se han transformado para dar paso a una nueva clase de lector, el usuario o internauta. Las narrativas digitales de LIJ han devuelto al lector el papel protagónico de que es merecedor pues en muchos casos sin su participación la historia no existiría, la obra quedaría inconclusa.

Internet y las tecnologías, nuevas formas de lectura

La inserción de tecnología en los procesos editoriales existe desde la invención de la imprenta, aparato que revolucionó el pensamiento de todo un siglo y que dio paso a la masificación de obras literarias.

Hoy en día, los medios de comunicación juegan un papel fundamental en la creación y transmisión de la obra literaria estableciendo una jerarquía de los sentidos a través de la forma de percibir y el orden epistémico que se han ido transformando con el tiempo (Chartier, 1996).

Los medios electrónicos no sólo transmiten información, la empacan y la filtran de acuerdo a las necesidades específicas de un público que creció con dichos medios y tecnologías: "los medios de comunicación extienden nuestros sentidos, han extendido y extrapolado vista y oído, alterando nuestra realidad cotidiana" (Lowe, 1982, p. 20).

El homo videns al que hacía referencia Sartori (1997), se ha convertido en el ser digital que Negroponte (1995) predijo, un ser ávido de obtener narrativas al alcance de su mano.

Las narrativas para niños y jóvenes actuales van más allá del uso de la imagen como lenguaje que se inició con el libro álbum, el cómic y la novela gráfica, los autores 1 crean y adaptan las obras a formatos digitales incluyendo movimiento, sonido e interacción; y agregando con ello nuevos modos de leer, de ver y de participar con los textos.

Al respecto hay que señalar que es diferente la adaptación de la extensión, la primera toma la historia de un medio y la traslada a otro. En cambio, la segunda, busca añadir algo más a la historia ya existente y la presenta por otro medio (Jenkins, 2011). Trasladar una obra de un formato a otro resulta siempre en una interpretación distinta de lo que se está viendo, añade nuevos significados que se van construyendo como capas de una misma historia.

Puesto que los libros electrónicos aparecieron mucho antes que la narrativa digital -en la década de los noventa-, el verdadero paso del papel a la pantalla surge en el siglo XXI con el uso de aplicaciones y herramientas que ponen en las manos del lector las historias, sean estas adaptaciones u obras creadas ex profeso para un formato digital. Así lo constatan la cantidad enorme de videojuegos, animaciones, apps, interactivos, que si bien no sustituyen a las obras de LIJ ni mucho menos restan importancia al libro impreso, replantean los modos de leer de los niños y jóvenes, transformando también la manera de contar historias, es decir, la creación.

La narrativa digital de LIJ no sólo surge por el cambio en los conceptos de creación, de autor y obra, su despunte es gracias a la producción y comercialización masiva de aparatos electrónicos que facilitan su rápida distribución: laptops, smartphones y tabletas. 
Incluso se ha formado una nueva oleada de autores que editan sus obras digitalmente en estas plataformas, la Generación Kindle o Generación Kindie (nombre que alude al aparato de lectura de libros digitales Kindle) o el caso del género llamado twitteratura, que son microhistorias de 140 caracteres escritas desde la red social Twitter.

En el caso de la LIJ, no es de sorprenderse que las narrativas dieran este salto, incluso estaba predestinado pues los "nativos digitales" (Cassany, 2008) que nacieron a la par del internet y las TIC -1998, cuando empieza a difundirse de manera masiva la world wide web-, están rodeados de imágenes y sonidos, para ellos no significa un reto interactuar con la pantalla. En cambio, los "migrantes digitales", acostumbrados al pasar de una hoja, tuvieron que adaptarse a los cambios que trajo consigo la computadora y el internet, lo que se traduce en una resistencia mayor a la lectura en formatos digitales.

\section{Redefiniendo la narrativa digital desde la LIJ}

Si bien se ha tratado de generar un concepto de narrativa digital desde diferentes disciplinas y posturas; las que intervienen en su creación, difusión y decodificación, es necesario plantear un concepto de narrativa digital para la LIJ.

Desde la Literatura, la narrativa se considera el género constituido por la novela, la novela corta y el cuento, aunque en el caso de la LIJ, el término va más allá de estos tres subgéneros. Guerrero (2012) hace una tipología funcional de la narrativa en LIJ definiéndola como el género teórico general que nace con la novela y el cuento literario del siglo XVIII. A su vez, esta narrativa se puede clasificar en modalidades temáticas y formales, que son producto del desarrollo histórico. El género narrativo, el architexto o "texto de textos", engloba un conjunto enorme de obras con rasgos específicos que las caracterizan:

En la narrativa el eje central es el relato de acontecimientos entretejidos en una trama imaginaria, la acción de contar o relatar hechos ficticios entretejidos en un argumento creado por el autor. La narrativa incluye subgéneros que son las especies incluidas dentro de un género, ya sea por razones de forma o tema. Estos subgéneros tienen modalidades, que son las características de tema o estilo que proporcionan un aspecto especial a la obra. Entre género y modalidad puede haber infinidad de cruces. (Guerrero, 2012, p. 39).

Desde las Teorías de la Comunicación, la narrativa digital se define como una dispersión de historias a través de diferentes medios y recursos, haciendo uso de las tres familias de signos: el verbal, el visual y el auditivo. (Turrión, 2014)

Por otro lado, aunque el término digital proviene de la Revolución digital2, época donde la informática y la telemática se volvieron la base de las sociedades globalizadas, Lamarca (2013) lo describe más como una característica de los documentos o textos. En relación a estos, la digitalidad será:

[...] la forma en que está codificada la información (en forma de bits) y, por otra parte, la necesaria mediación de un ordenador para descodificar esta información, porque para leer, visualizar o grabar la información se precisa de un dispositivo que transmita o grabe información codificada en bits. (Lamarca, párr. 8)

Otra característica de la narrativa digital es la inclusión de elementos hipertextuales, lo que hace posible contar una o varias historias al mismo tiempo: 
El hipertexto conecta un pasaje de discurso verbal a imágenes, mapas, diagramas y sonido tan fácilmente como a otro fragmento, expandiendo la noción de texto más allá de lo meramente verbal. El hipertexto, refiere a un medio informático que relaciona información tanto verbal como no verbal. (Landow, 1995, p. 15)

Siguiendo lo anterior, una obra de narrativa digital en LIJ será aquella que hace uso de tecnologías digitales en su creación, transmisión y en la recepción de las obras; que además introduce elementos multimodales: sonido, imágenes, animación, texto, interactividad y que puede incluir elementos hipertextuales.

Además, estas obras deben cumplir con la característica de literaturidad que sustenta la teoría literaria, definida ésta en términos de su relación con una realidad supuesta, como discurso ficticio o imitación de los actos del lenguaje cotidiano:

El lenguaje escrito como lo conocemos hoy es el medio de expresión que permite la comunicación de ideas y la transferencia de información entre las sociedades. El lenguaje también puede poseer otra finalidad además de la comunicativa, esta finalidad puede ser expresiva o artística y ha dado paso a lo que conocemos como Literatura. La Literatura a diferencia del lenguaje ordinario, se caracteriza por enaltecer el espíritu, recrearlo y proporcionarle una experiencia que ayuda a conectarnos con el mundo interno. Esta característica de los textos se llama literaturidad. (Culler, 1993, p. 38)

La narrativa digital de LIJ conserva su esencia literaria al estar dotada de los elementos y características propios de la disciplina pero, su diferencia en la manera de construir el discurso, valiéndose de los lenguajes y la estructura de otras disciplinas, la hace una obra de arte completa; por ello no debe ser encasillada sólo dentro de los cánones literarios. En todo caso, la narrativa digital es más un conglomerado de discursos culturales que confluyen todos al unísono en la pantalla.

Posibilidades de la LIJ digital

Los ejemplos que se presentan a continuación son muestra de la multiplicidad de opciones que actualmente conforman la LIJ digital. A pesar de sus características comunicacionales, literarias y tecnológicas, la forma tan rápida en que emergen las obras deja siempre la posibilidad de establecer una tipología desde otras aproximaciones.

Se puede, por ejemplo, usar la clasificación de Turrión (2014) quien las distingue de acuerdo a los elementos que la componen en: audiolibros digitales, narrativa multimedia, hipermedia, multisoporte o multiplataforma. Dejando de lado el primer grupo, que sólo implicaría el cambio de formato de análogo a digital limitándose al lenguaje sonoro; los otros tres son importantes para definir características en las obras.

Un ejemplo de la primera, la narrativa multimedia -que hace uso de los lenguajes escrito, sonoro y de la imagen- es la adaptación digital del libro álbum El hombre de agua (2009), del escritor Ivo Rosati e ilustrado por Gabriel Pacheco. La historia fue animada por el estudio coreano Earth Design Works3, lo que resultó en un cortometraje con duración de 1:30 minutos. En la adaptación se respetaron las ilustraciones originales y se agregaron nuevos elementos -música original, animación, texturas- que cambian considerablemente la manera de percibir la historia, conjugando diferentes disciplinas que dan como resultado un producto digital de gran riqueza narrativa y audiovisual. 
La narrativa hipermedia, es aquella que hace uso de diversos lenguajes y de una estructura hipertextual, por medio de enlaces se llega a información adicional que está fuera de la historia base, pero que la complementa.

Un ejemplo de esta narrativa es el libro álbum El edificio (2014), del escritor Jairo Buitrago e ilustrado por Daniel Rabanal que presenta una excelente propuesta estética y narrativa. En su versión digital4 , la secuencia de imágenes animadas aporta una atmósfera especial que acerca al lector al microcosmos de La Favorita, un barrio que tiene gran historia en Bogotá.

Además de la historia lineal que van contando las imágenes y la música original, es posible conocer más detalles gracias al mapa incluido en la versión para pantalla, desde el cual se accede a edificios y calles emblemáticas del barrio, mostrando documentos y fotografías que son parte de un archivo histórico. El libro álbum digital reconoce también la importancia de la creación, por ello se insertaron las biografías del autor, los músicos, los animadores; datos que acercan al lector final con la obra.

Dentro de la narrativa multisoporte o multiplataforma, que es una dispersión de historias en diferentes soportes o plataformas, se encuentran obras como el cortometraje animado The Fantastic Flying Books of Mr. Morris Lessmore (2011), ganador de un Premio Óscar, una narrativa que se expande a través de diferentes medios.

La historia creada especialmente para la pantalla, da cuenta del amor que tiene el señor Morris Lessmore para con los libros que encuentra abandonados en una biblioteca tras un desastre natural. La animación derivó en un libro álbum y una aplicación para iPad que se activa mediante la lectura del texto impreso en el libro, desplegando efectos de realidad aumentada donde los personajes y escenarios parecen salir de las páginas5 .

Otra manera de clasificar la LIJ digital es tomando en cuenta el nivel de interacción entre el dispositivo, el usuario y la obra.

En un nivel bajo, existe poca participación del usuario con la obra, pudiendo considerarse un lector pasivo6 , ya que únicamente está capacitado para acceder a la historia a través de la pantalla, interactuando de manera muy básica, poniendo play, pausa o incluso repitiendo escenas de su agrado. También puede interactuar aprobando o desaprobando las obras por medio de la web, en redes sociales o dando like a las páginas y aplicaciones que encuentra, lo que imposibilita que la historia tome un rumbo diferente.

En esta categoría incluimos el libro álbum Yo espero (2005) ilustrado por Serge Bloch7 que se adaptó al formato digital en una aplicación para iPad. La obra resulta en una narrativa hipermedia donde los lectores siguen el curso de la historia a través de la interacción mínima con la pantalla. La lectura se vuelve multisensorial al incluir otros sentidos además de la vista (el tacto y el oído); conectando los elementos sonoros y visuales para expandir el relato más allá de lo meramente verbal, contrario a lo que sucede en el formato del libro álbum.

La historia cuenta la leyenda asiática El hilo de la vida, una metáfora de las etapas de la vida que van desde el nacimiento hasta la muerte. En la app el usuario debe arrastrar con su dedo el hilo rojo sobre la pantalla y con ello hacer avanzar la historia. Al tiempo que suceden las acciones plasmadas en las ilustraciones, el narrador omnipresente va contando la historia8 .

En un nivel medio, el dispositivo permite activar otros elementos como imágenes, sonidos, textos complementarios o ventanas emergentes que intensifican la relación entre obra y lector. 
En la aplicación iPoe collection Vol. 1, los cuentos de Edgar Allan Poe: El retrato oval, El corazón delator, Anabel Lee y La máscara de la muerte roja son resignificados a través de los medios digitales. El libro ilustrado e interactivo cuenta con innumerables recursos gráficos y sonoros que el usuario va descubriendo conforme avanza en los relatos, lo cual aporta nuevos significados a través de una experiencia sensorial única. Antes de comenzar los relatos se sugiere al lector que use audífonos para intensificar la experiencia.

En un nivel alto de interacción, la narrativa digital permite al usuario modificar la historia, ya sea porque elige una decisión que afecta la secuencia del relato o porque puede cambiar de manera consciente uno de sus elementos.

Este tipo de relatos se asemejan más a las estructuras no lineales usadas en medios visuales como el cine, las series de televisión o los juegos de mesa. Su característica disociativa hace posible acceder a la narrativa por medio de la exploración consciente e inconsciente de otras opciones, cambiarlas e incluso terminarlas en el momento deseado, sin necesariamente llegar al final.

Ejemplo de esto es el libro álbum digital Spot (2015), del ilustrador David Wiesner. Spot es una aplicación que permite una experiencia inmersiva donde el usuario va creando la narrativa al seleccionar diferentes mundos y escenarios, que pueden ser hasta cinco: tiny world, space world, underwater world, cat world y robot world, cada uno con temáticas particulares. Una mezcla perfecta entre libro álbum y aplicación digital donde la lógica del relato es una especie de zoom de las ilustraciones, en cada imagen el usuario descubre un detalle que lo hace adentrarse más y más en la historia que él decide o no seguir. Al encontrarse con diferentes objetos, el lector tiene un compendio de opciones en la pantalla que va descubriendo poco a poco, de acuerdo a sus intereses y gustos personales, como una carretera con múltiples caminos a seguir.

Esta narrativa estaría en un nivel superior a las dos anteriores puesto que, además del uso del dispositivo digital, la historia no lineal permite al espectador crear conexiones lógicas entre lo que se está presentando en pantalla ya sea de manera textual, visual, auditiva o multimedia y también exige una forma distinta de acceder a la historia, tomando como protagonista al lector.

\section{Conclusiones}

Las diferentes formas de contar historias en las narrativas digitales de LIJ han hecho de las pantallas una interfaz privilegiada mediante la cual los contenidos son percibidos en todo su esplendor, lo que permite reconocer en ellas características comunicacionales, literarias y artísticas.

La interfaz, en este caso las pantallas, son "el vehículo de acceso en los procesos donde existe un intercambio o transferencia de información, mediante interfaces gráficas accedemos al contenido de textos, que no son otra cosa que representaciones de imágenes, ideas; letras, signos, símbolos, grafías, es decir iconos" (Scolari, 2004, p. 19).

Por medio de estas interfaces los niños y jóvenes tienen la posibilidad de conocer representaciones de su entorno, aquellas que forman parte de su realidad y al mismo tiempo las de mundos imaginarios y fantásticos.

Cada texto genera un lector y cada interfaz construye un usuario definido, los medios tradicionales han mutado a los digitales, los usuarios que poseen experiencias hipertextuales e inmersivas están completamente distantes 
de la lógica lineal de la transmisión y emisión unidireccional (Scolari, 2008), estos usuarios, son los niños y jóvenes que nacieron con dichas tecnologías.

La interfaz establece comunicación entre nuestro sistema humano y el entramado digital de un medio tecnológico mayormente visual. De esta manera el proceso de acercamiento a las historias es diferente al que se tenía hasta hace algunos años, pues aunque ya existían la imagen en movimiento y el sonido -en el cine, el video, los dibujos animados-; la manera de asimilar y de acceder a estas historias, por medio de la pantalla e internet, han dado un paso más en la creación y recepción de las obras.

En la actualidad la interfaz ha evolucionado haciendo que el usuario sea parte de ella. Las pantallas a lo largo de la historia, han ido acercando al lector, al receptor, al espectador, al usuario con el mensaje, la obra, el texto; para integrarlo, sea con el pasar de una página o con el toque del dedo para accionar o mover un elemento interactivo: "la interfaz ya no está fuera de nosotros sino que cada vez, con los dispositivos digitales, es parte de nuestro cuerpo" (Escandón, 2013).

En pleno siglo XXI el libro como soporte, como interfaz de acceso a la información, ha perdido su poder frente a los nuevos medios de lectura, se ha bajado de su lugar privilegiado como único dador de saberes en la cultura. Los lectores del siglo XXI necesitan nuevos modos de comunicarse, de relatar su(s) historia(s) y de acceder a ella(s). No se trata de hacer comparativos entre la cultura del texto escrito y la cultura de los medios digitales, sin embargo, es necesario poner de manifiesto que las narrativas digitales, en específico las de LIJ, otorgan al lector una experiencia de lectura diferente, que está desplazando muchos de los conceptos y términos que trajo consigo el libro como objeto cultural.

La narrativa digital de LIJ es una neovanguardia literaria que pone como eje central y punto de partida al lector, al contenedor de todos los saberes. Los usuarios de estas plataformas aprehenden los relatos, los hacen suyos; esta transformación ayuda a comprender que cada generación opera bajo sus propias reglas, haciendo uso de las herramientas que tiene a la mano, lo cual abre un mundo de posibilidades y de nuevos paradigmas.

Notas

1. Consideramos no usar más el término escritor pues en las obras digitales también existen otros autores que no precisamente son escritores, ahora son animadores, diseñadores, pintores, fotógrafos, etc.

2. La era digital se sitúa a finales del siglo $X X$ y principios del $X X I$, producto de los desarrollos tecnológicos y la invención de internet, trajo consigo cambios sociales que ayudaron a la creación de una cultura masificada de los medios digitales.

3. El corto animado se puede consultar desde la dirección: https://vimeo.com/66372995

4. Para observar un promocional del libro álbum digital, dirigirse a la siguiente página: https://www.youtube.com/watch?v=aNp2knd714Y

5. Para conocer el funcionamiento de la app de realidad aumentada ver el siguiente video: https://www.youtube.com/watch?v=AiV0zxTXQPc 
6. Es importante aclarar que no se hace referencia a un lector pasivo o activo como se determina desde las teorías literarias enfocadas en la experiencia lectora, más bien se describe aquí una lectura pasiva o activa en relación a la interacción física con el dispositivo digital desde donde el usuario accede a la narrativa.

7. Serge Bloch (Colmar, Francia, 1956) ha trabajado en publicidad y prensa, sus ilustraciones se caracterizan por un trazo sencillo, casi infantil, llenas de humor, ironía y gran expresividad. A veces sus dibujos se insertan en retazos de fotografías, usa el collage y técnicas mixtas. También hace uso del video y animación para dar vida a sus ilustraciones. Para conocer más su obra visitar: http://www.sergebloch.net/

8. Para observar el funcionamiento de la app ver el siguiente video, disponible en: https:// www.youtube.com/watch?v=xjjkuQHUXjc

\section{Referencias}

Barthes, R. (1968). La muerte del autor. Recuperado de http://www.cubaliteraria.cu/revista/ laletradelescriba/n51/articulo-4.html

Buitrago, J. \& Rabanal, D. (2014). El edificio. Bogotá: Babel. . (2016). El edificio, un cómic digital. Colombia: Manuvo.

Cali, D. \& Bloch, S. (2005). Yo espero. México: SM.

Cali, D. \& Bloch, S. (2013). Moi, J'attends. Francia: France Televisions Distribution SA.

Cassany, D. (2008). Prácticas letradas contemporáneas. México: Ríos de Tinta.

Chartier, R. (1996). Del códice a la pantalla: Trayectorias de lo escrito. Revista Quimera \#150. Recuperado de http://www.javeriana.edu.co/relato_digital/r_digital/bibliografia/ virtual/chartier-completo.html

Culler, J. (1993). Teoría literaria. México: Siglo XXI.

Escandón, P. (2013). La pantalla, un papiro evolucionado. Revista ensayos. Quito.

García, D. (2016). iPoe collection Vol. 1. Relatos originales: Edgar Allan Poe. España: Play Creatividad.

Guerrero, L. (2012). Posmodernidad en la Literatura infantil y juvenil. México: UIA. . (2016). Neosubversión en la LIJ contemporánea. Una aproximación a México y España. México: UIA.

Jenkins, H. (2001). Transmedia 202: reflexiones adicionales. Recuperado de http://henry jenkins.org/ Joyce, W. \& Oldenburg, B. (2011). The Fantastic Flying Books of Mr. Morris Lessmore. EUA: Moonbot Studios. Joyce, W. \& Bluhm, J. (2012). Los fantásticos libros voladores del Sr. Morris Lessmore. Madrid: Alfaguara. 
Kim, Y., Kim, J., Ko, J., Park, H., Choun, S. (2013). The Memory of Fountain (L'uomo d'acqua e la sua Fontana). Corea: Earth Design Works.

Lamarca, M. (2013). Hipertexto: el nuevo contexto de documento en la cultura de la imagen. Recuperado de http://www.hipertexto.info/

Landow, G. (1995). Hipertexto: la convergencia de la teoría crítica contemporánea y la tecnología. Barcelona: Paidós.

Lowe, D. (1986). Historia de la percepción burguesa. México, D.F: FCE.

Nobile, A. (1992). Literatura infantil y juvenil. La infancia y sus libros en la civilización tecnológica. España: Morata.

Primera Encuesta Nacional sobre Consumo de Medios Digitales y Lectura. (2015). México: IBBY, ANUIES, CIDE, El Colegio de la Frontera Norte, FCE, UAM, IBERO, UNAM, Instituto de Investigaciones Jurídicas. Recuperado de http://www.ibbymexico.org.mx/ images/ENCUESTA_DIGITAL_LECTURA.pdf

Pokémon Go. (2016). The Pokémon Company. Recuperado de http://www.pokemongo. com/es-es/

Rey, M. (2000). Historia y muestra de la literatura infantil mexicana. México: Conaculta-SM.

Rosati, I. \& Pacheco, G. (2009). El hombre de agua. España: Kalandraka.

Scolari, C. (2004). Hacer Clic: Hacia una sociosemiótica de las interacciones digitales. Barcelona: Gedisa. (2008). Hipermediaciones. Elementos para una teoría de la comunicación digital interactiva. Barcelona: Gedisa.

The Fantastic Flying Books of Mr. Morris Lessmore. (2013). EUA: Moonbot Studios.

Turrión, C. (2014). Narrativa infantil y juvenil. ¿Qué ofrecen las nuevas formas al lector literario? (Tesis de doctorado inédita). Universitat Autònoma de Barcelona: España.

Wiesner, D. (2015). Spot. EUA: Houghton Mifflin Harcourt.

Abstract: In children's and youth digital literature, the technologies are used not only for create the narrative but also for their transmission and reception, throughout the screen such as privileged interface. This included multimodal elements; it means, text and images are attached by sounds, animation, interactivity and hypertextual components that's appeal to an interactive reader, who converts in hiper reader. In this way the narrative gender, expands their possibilities. This article provides a critical perspective about the virtual literature manifestations, particularly, in the children's and youth literature, through interdisciplinary analysis.

Key words: digital narrative - children's and youth literature - hypertext - hiper reader. 
Resumo: Na literatura infantojuvenil digital, as tecnologias são utilizadas não só para a criação da narrativa, mas também para a transmissão e recepção através das telas como uma interface privilegiada. Nas quais incluem; se elementos multimídia; ou seja, texto e imagens se unem sons, animação, interatividade e componentes hipertextuais que apelam ao leitor ativo e convertê lo em um hiperleitor. Assim, a narrativa, como gênero, amplia suas possibilidades. O presente trabalho explora criticamente o panorama de eventos literários virtuais, em particular, os da literatura infanto juvenil, a partir da análise interdisciplinar.

Palavras chave: narrativas digitais - literatura infanto juvenil - hipertexto - hiperleitor.

[Las traducciones de los abstracts al inglés y portugués fueron supervisadas por el autor de cada artículo]

Nuevos soportes, nuevos modos de leer. La narrativa en la Literatura infantil y juvenil digital fue publicado de la página 45 a página58 en Cuadernos del Centro de Estudios de Diseño y Comunicación №72 